\title{
Maternal perinatal diet induces developmental programming of bone architecture
}

\author{
M J Devlin 1,5,*, C Grasemann 3,4,*, A M Cloutier', L Louis', C Alm³, M R Palmert ${ }^{3}$ \\ and $M L$ Bouxsein ${ }^{1,2}$
}

${ }^{1}$ Beth Israel Deaconess Medical Center, Boston, Massachusetts, USA ${ }^{2}$ Harvard Medical School, Boston, Massachusetts, USA ${ }^{3}$ Hospital for Sick Children, The University of Toronto, Toronto, Ontario, Canada ${ }^{4}$ Kinderklinik UK-Essen, The University of Duisburg-Essen, Essen, Germany ${ }^{5}$ Department of Anthropology, University of Michigan, 101 West Hall, 1085 S. University Ave., Ann Arbor, Michigan 48108, USA

*(M J Devlin and C Grasemann contributed equally to this study and are considered as co-first authors.)

\author{
Correspondence \\ should be addressed to \\ M J Devlin \\ Email \\ mjdevlin@umich.edu
}

\begin{abstract}
Maternal high-fat (HF) diet can alter offspring metabolism via perinatal developmental programming. This study tests the hypothesis that maternal HF diet also induces perinatal programming of offspring bone mass and strength. We compared skeletal acquisition in pups from C57BI/6J mice fed HF or normal diet from preconception through lactation. Three-week-old male and female pups from HF (HF-N) and normal mothers (N-N) were weaned onto normal diet. Outcomes at 14 and 26 weeks of age included body mass, body composition, whole-body bone mineral content (WBBMC) via peripheral dual-energy $X$-ray absorptiometry, femoral cortical and trabecular architecture via microcomputed tomography, and glucose tolerance. Female HF-N had normal body mass and glucose tolerance, with lower body fat (\%) but higher serum leptin at 14 weeks vs $\mathrm{N}-\mathrm{N}(P<0.05$ for both). WBBMC was $12 \%$ lower at 14 weeks and 5\% lower at 26 weeks, but trabecular bone volume fraction was $20 \%$ higher at 14 weeks in female HF-N vs $N-N(P<0.05$ for all). Male HF-N had normal body mass and mildly impaired glucose tolerance, with lower body fat (\%) at 14 weeks and lower serum leptin at 26 weeks vs $N-N(P<0.05$ for both). Serum insulin was higher at 14 weeks and lower at 26 weeks in HF-N vs N-N $(P<0.05)$. Trabecular BV/TV was $34 \%$ higher and cortical bone area was $6 \%$ higher at 14 weeks vs $N-N(P<0.05$ for both). These data suggest that maternal HF diet has complex effects on offspring bone, supporting the hypothesis that maternal diet alters postnatal skeletal homeostasis.
\end{abstract}
Key Words
- skeletal biology
- skeletal development
- nutrition
- mouse
- bone formation
- resorption

Journal of Endocrinology (2013) 217, 69-81

\section{Introduction}

Osteoporosis and obesity are increasingly prevalent diseases in the USA, with $50 \%$ of women and $20 \%$ of men over age 50 predicted to suffer an osteoporotic fracture in their remaining lifetime and two thirds of adults and $19 \%$ of children in the USA being overweight or obese (Ogden et al. 2007, U.S. Department of Health and Human Services, 2004). The recent discovery of interactions between bone, fat, and the brain raises the possibility that these diseases may share common origins (Rosen \& Bouxsein 2006). As obesity and osteoporosis are examples of so-called 'later in life diseases', which might be programmed very early in life, their origins may lie in the 
perinatal environment. Previous studies have demonstrated that maternal nutrition, including the mother's diet during gestation and lactation, can markedly increase the risk of metabolic diseases, such as obesity and type II diabetes (Ozanne et al. 2004, Boney et al. 2005). The mechanism underlying these effects is known as perinatal developmental programming, defined by Lucas (1991) as 'a stimulus or insult at a critical period of development (that) has lasting or lifelong significance'. However, little is known about whether maternal diet causes developmental programming of bone mass acquisition and/or of the skeletal response to postnatal diet. If maternal diet induces programming that alters the balance between fat mass and bone mass in offspring, particularly during rapid childhood growth, then maternal diet may be a modifiable risk factor for both osteoporosis and obesity (Cooper et al. 2006).

We hypothesize that maternal high-fat (HF) diet induces perinatal developmental programming of postnatal skeletal acquisition, bone mass, and strength, as well as metabolism. There are many potential factors that could affect the balance between metabolism, fat, and bone and thereby underlie the effects of perinatal diet on skeletal acquisition, including adipokines such as leptin (Thomas et al. 1999, Cornish et al. 2002, Patel \& Elefteriou 2007), either directly or via hypothalamicmediated $\beta$-adrenergic signaling (Ducy et al. 2000, Takeda et al. 2002, Elefteriou et al. 2005); osteocalcin as a bonederived hormone that controls energy metabolism (Lee et al. 2007); the GH-insulin-like growth factor 1 (IGF1) axis (Rosen 2000); and levels of gonadal steroids and timing of sexual maturation (Chevalley et al. 2009). Leptin is a particularly strong candidate mediator given its multiple roles in energetic, reproductive, and skeletal homeostasis (Hamrick 2004). Moreover, maternal HF diet is known to induce perinatal programming of leptin sensitivity in the ventromedial hypothalamus (Bonnet et al. 2008). Postnatally, peripheral leptin is anabolic to cortical bone via leptin receptors, but leptin signaling via the hypothalamus and/or the leptin-serotonin axis inhibits bone mass accrual, in part via increased sympathetic tone that activates $\beta$-adrenergic receptors on osteoblasts (Yadav et al. 2011). Thus, perinatal programming of leptin sensitivity has the potential to alter the balance between cortical and trabecular bone mass. Furthermore, osteoblasts and adipocytes derive from a common mesenchymal stem cell progenitor, such that increased differentiation of one cell type might decrease differentiation of the other cell type (Rosen \& Bouxsein 2006, Cao 2011). Indeed, there is some evidence for inverse correlations of bone mass and fat mass in young as well as in older individuals (Wren et al. 2011).

Here, we test the effect of maternal perinatal HF diet on postnatal acquisition of bone mass, microarchitecture, and strength by comparing postnatal bone mass, fat mass, and metabolic phenotype in mice whose mothers were fed HF vs normal $(\mathrm{N})$ diets during gestation and lactation, but who themselves were fed a normal diet postnatally. If, as predicted, maternal HF diet induces developmental programming of pathways mediating skeletal as well as metabolic homeostasis, then we expect offspring of HF diet mothers to exhibit both higher fat mass and lower bone mass compared with offspring of $\mathrm{N}$ diet mothers. We would expect a similar pattern if maternal HF diet influences offspring bone mass via induction of metabolic changes (such as impaired glucose tolerance or obesity) that are deleterious to skeletal acquisition. An alternative possibility is that maternal HF diet affects offspring bone mass and metabolism via different mechanisms, such that changes in skeletal acquisition can occur independent of changes in metabolism.

\section{Materials and methods}

All animal studies were approved by the local Animal Care Committee (AUP 09-08-0097) in accordance with recommendations of the Canadian Council on Animal Care, the requirements under Animals for Research Act, RSO 1980, and the Toronto Centre for Phenogenomics (TCP) Committee Policies and Guidelines. Experimental mice were maintained under controlled conditions $\left(25^{\circ} \mathrm{C}, 12 \mathrm{~h}\right.$ light: $12 \mathrm{~h}$ darkness cycle) at the TCP. C57Bl/6J mice were obtained through Jackson Laboratories (Bar Harbor, ME, USA; stock number 000664) and a colony was established at the TCP.

Dams were bred at 12-18 weeks of age and were of similar body habitus. Males were removed after 3 days of breeding. Females were housed in pairs for 14 days and then moved to individual cages. Offspring were nursed by birth mothers and weaned on day 21 according to sex with a maximum of five mice per cage. Number of dams, litter size, and sex distribution did not differ between HF litters and control litters. In a subgroup of animals, fasted maternal and paternal serum glucose concentrations were measured before mating and on day 17 of pregnancy. For this purpose, males were paired with females for $24 \mathrm{~h}$ only.

Published by Bioscientifica Ltd. 


\section{Dietary intervention}

Dams were fed normal or HF diet ad libitum for 6 weeks before breeding and continuing through gestation and lactation. The $\mathrm{N}$ diet was Harlan Teklad Global $2018,18 \% \mathrm{KCal} / \mathrm{fat}$ ( $6.2 \%$ fat by weight, comprised $16 \%$ saturated, $21 \%$ monounsaturated, and $61 \%$ polyunsaturated; cholesterol $0 \mathrm{mg} / \mathrm{kg}$ ). The HF diet was Harlan Teklad (Indianapolis, IN, USA) TD 06415, 45\% kCal/fat $(22.7 \%$ fat by weight, comprised $36 \%$ saturated, $47 \%$ monounsaturated, and $17 \%$ polyunsaturated; cholesterol $230 \mathrm{mg} / \mathrm{kg}$ ). At 3 weeks of age, male and female pups from HF (HF-N) and normal (N-N) mothers were weaned onto $\mathrm{N}$ diet ad libitum. Mice were killed by $\mathrm{CO}_{2}$ inhalation at 14 or 26 weeks of age ( $n=9-19 /$ group).

\section{Intraperitoneal glucose tolerance test}

Dams on normal chow and on HF diet were tested before breeding and at the time of weaning. Male and female offspring were tested at 14 and 26 weeks of age. Intraperitoneal glucose tolerance tests (IPGTTs) were performed after a 6-h fast. Following a baseline fasted blood sample from the tail vein (Contour Glucometer, Bayer), mice were injected i.p. with filtered, sterile glucose $(200 \mathrm{mg} / \mathrm{ml})$ at $2 \mathrm{~g}$ glucose $/ \mathrm{kg}$ bodyweight. Further samples were taken at 30,60 , and $120 \mathrm{~min}$ after the injection. Values for area under the curve (AUC) of glucose measurements at $0,30,60$, and 120 min were calculated as $\mathrm{AUC}=1 / 2 \Sigma\left(t_{i+1}-t_{i}\right)\left(y_{i}+y_{i+1}\right)$ where $t$, time point and $\mathrm{y}$, measurement (Matthews et al. 1990).

\section{Peripheral dual-energy X-ray absorptiometry}

Assessment of whole-body (exclusive of the head region) bone mineral density (WBBMD $\left(\mathrm{g} / \mathrm{cm}^{2}\right)$ ), bone mineral content (WBBMC (g)), and body composition (body fat (\%)) was performed at killing using peripheral dual-energy X-ray absorptiometry (pDXA, PIXImusII, GE Lunar Corp., Madison, WI, USA), as described previously (Bouxsein et al. 2005, 2009, Ferrari et al. 2005).

\section{Specimen harvesting/preparation}

Femurs were harvested and cleaned of soft tissue. The right femur was prepared for imaging and biomechanical testing by wrapping in saline-soaked gauze and freezing at $-20^{\circ} \mathrm{C}$. The left femur was prepared for histology in $10 \%$ neutral buffered formalin at $4{ }^{\circ} \mathrm{C}$ for $48-72 \mathrm{~h}$ and then transferred to $70 \%$ ethanol at $4{ }^{\circ} \mathrm{C}$.

\section{Trabecular and cortical bone morphology by microcomputed tomography}

Assessment of bone morphology and microarchitecture was performed with high-resolution microcomputed tomography $(\mu \mathrm{CT} 40$, Scanco Medical, Brüttisellen, Switzerland) of the distal femoral metaphysis and L5 vertebral body, as described previously (Glatt et al. 2007). Although the proximal femur is of particular relevance for human osteoporosis, mice have little trabecular bone at this site, so the distal femur is frequently used (Bouxsein et al. 2010). In brief, specimens were scanned using an X-ray energy of $70 \mathrm{KeV}$, integration time of $200 \mathrm{ms,}$ and a $12 \mu \mathrm{m}$ isotropic voxel size. For the cancellous bone region, we assessed bone volume fraction (BV/TV (\%)), trabecular thickness (Tb.Th $(\mathrm{mm}))$, trabecular separation (Tb.Sp $(\mathrm{mm}))$, trabecular number (Tb.N $(/ \mathrm{mm}))$, connectivity density (Conn.D $\left(/ \mathrm{mm}^{3}\right)$ ), and structure model index (SMI). Transverse CT slices were also acquired at the femoral midshaft to assess total cross-sectional area, cortical bone area and medullary area (TA, BA, and MA $\left.\left(\mathrm{mm}^{2}\right)\right)$, bone area fraction $(\mathrm{BA} / \mathrm{TA}(\%))$, cortical thickness $(\mu \mathrm{m})$, and area moments of inertia (maximum, $I_{\max } ;$ minimum, $I_{\min }$; and polar, pMOI $\left.\left(\mathrm{mm}^{4}\right)\right)$ (Selker \& Carter 1989). Terminology and units followed the 2010 guidelines of the Journal of Bone and Mineral Research (Bouxsein et al. 2010).

\section{Bone strength testing}

Following $\mu \mathrm{CT}$ scanning, the strength of the femoral midshaft was assessed by three-point bending (by applying a flexion moment in the anterior-posterior plane) using previously described methods (Bouxsein et al. 2009). Briefly, specimens were thawed to room temperature in a calcium-buffered saline bath to ensure adequate hydration. A low-force mechanical testing system (Bose Electroforce 3230, with $100 \mathrm{~N}$ load cell) was used to apply constant displacement rate of $0.03 \mathrm{~mm} / \mathrm{s}$. The distance between load supports was $8.0 \mathrm{~mm}$ for 6 weeks and $10.0 \mathrm{~mm}$ for 12-week-old mice. Force-displacement data were used to determine structural properties (ultimate moment $(n \times \mathrm{mm})$, bending stiffness $(\mathrm{N} \times \mathrm{mm} / \mathrm{mm})$, and post-yield displacement $(\mathrm{mm})$ ) and then data for each specimen were adjusted for the appropriate femoral midshaft area moment of inertia, as measured on the $\mu \mathrm{CT}$ scans, to derive estimated elastic modulus (GPa).

\section{Serum hormones and bone turnover markers}

Blood was collected at killing after a 6-h fast by cardiac puncture for measurement of serum leptin by ELISA

Published by Bioscientifica Ltd 
(Crystal Chem, Downers Grove, IL, USA; Motyl \& McCabe 2009), serum insulin by ELISA (ALPCO, Windham, NH, USA), and serum IGF1 by RIA (ALPCO) as described previously (Bouxsein et al. 2002). Serum bone formation and resorption markers, type 1 procollagen N-terminal (P1NP) and collagen type 1 cross-linked C-telopeptide (CTX), were measured by ELISA (Immunodiagnostic Systems, Scottsdale, AZ, USA).

\section{Histology and quantitative histomorphometry}

Qualitative histological analysis and quantitative static and dynamic histomorphometry were performed as described previously (Gazzerro et al. 2005). To examine bone formation rates (BFRs), calcein labels $(15 \mathrm{mg} / \mathrm{kg})$ were injected i.p. at 9 and 2 days before killing. Histomorphometric measurements were performed on undecalcified sections in the secondary spongiosa of the distal femoral metaphysis using an OsteoMeasure morphometry system (Osteometrics, Atlanta, GA, USA). For dynamic histomorphometry, mineralizing surface per bone surface (MS/BS (\%)) and mineral apposition rate (MAR $(\mu \mathrm{m} /$ day)) were measured in unstained sections under u.v. light and used to calculate BFR with a surface referent (BFR $\left(\mu \mathrm{m}^{3} / \mu \mathrm{m}^{2}\right.$ per year)). Static measurements included eroded surface per BS (ES/BS (\%)), the numbers of osteoblasts per total area (N.Ob/T.Ar $\left.\left(/ \mathrm{mm}^{2}\right)\right)$, osteoclasts per total area (N.Oc/T.Ar
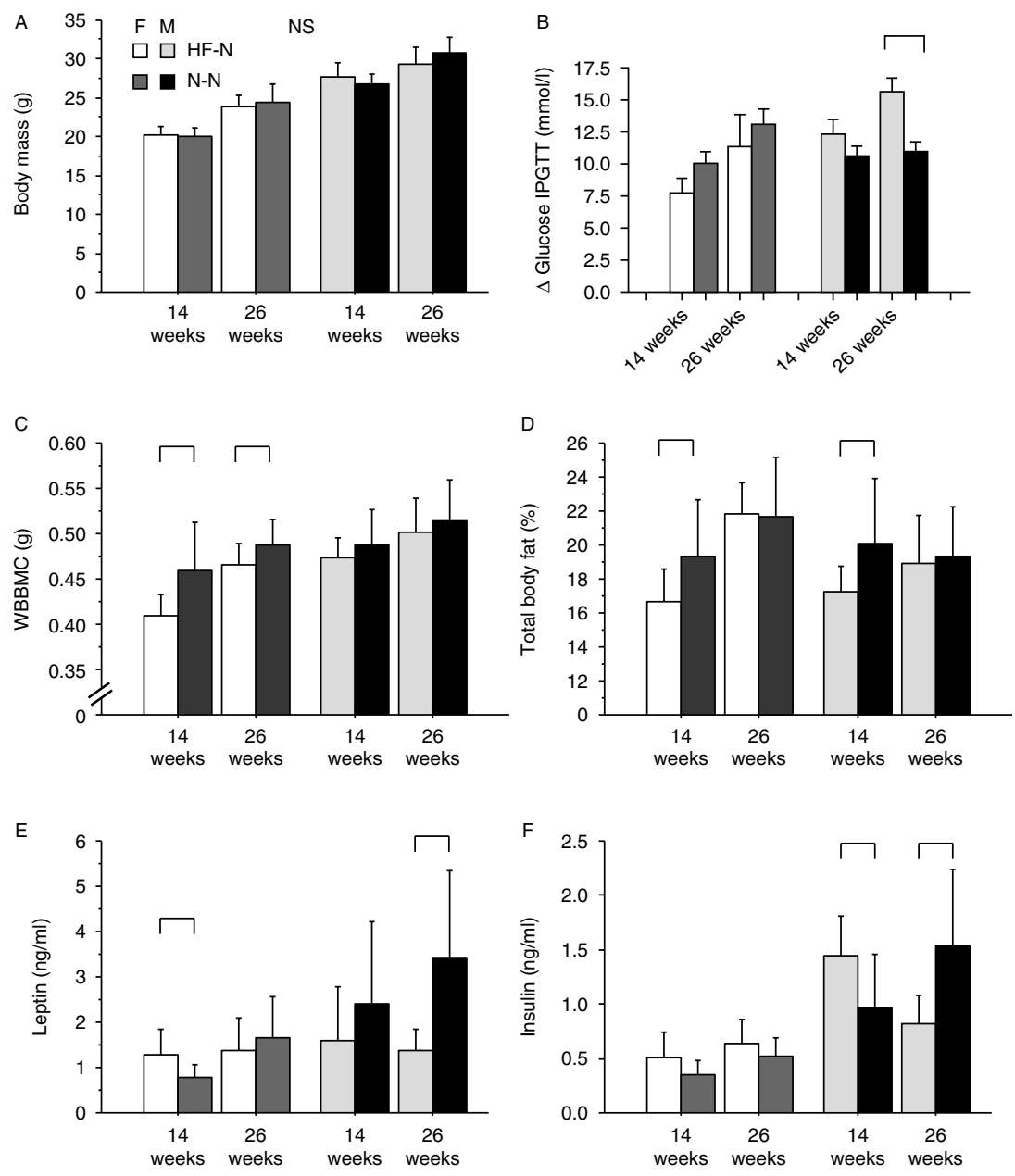

\section{Figure 1}

Body mass, glucose tolerance, whole-body bone mineral content, total body fat, and serum leptin and insulin in female and male offspring of $\mathrm{N}-\mathrm{N}$ or HF-N diet mothers, weaned to $\mathrm{N}$ diet from 3 weeks of age to 14 or 26 weeks of age. (A) Body mass (g; $n=9-16 /$ group),

(B) glucose tolerance ( $\mathrm{mmol} / \mathrm{l} ; n=9-43 /$ group), (C) WBBMC (g; $n=9-16 /$ group), (D) total body fat (\%; $n=8-12 /$ group), (E) leptin (ng/ml; $n=7-13 / g r o u p)$, and (F) insulin ( $\mathrm{ng} / \mathrm{ml} ; 6-13 /$ group). Brackets indicate significant differences $(P<0.05)$. 
$\left.\left(/ \mathrm{mm}^{2}\right)\right)$, and osteocytes per total area (N.Ot/T.Ar $\left.\left(/ \mathrm{mm}^{2}\right)\right)$. Marrow adiposity was quantified on toluidine blue-stained sections by measuring adipocytes per total area (N.Ad/T.Ar $\left(/ \mathrm{mm}^{2}\right)$ ) and mean adipocyte diameter $(\mathrm{mm})$, as described previously (Gazzerro et al. 2005). Terminology and units followed the recommendations of the Histomorphometry Nomenclature Committee of the American Society for Bone and Mineral Research (Parfitt et al. 1987).

\section{Statistical analyses}

Standard descriptive statistics were computed for all outcome variables, and data were checked for normality. The effects of diet, sex, and age on bone variables were evaluated using multifactorial ANOVA, followed by post hoc Fisher's protected least significant difference (PLSD) tests between groups if the effect of diet was significant in the overall model. All tests were two tailed, with the significance level for major effects set at $\alpha=0.05$.

\section{Results}

\section{Metabolism, body composition, and hormone levels}

Dams Maternal HF feeding resulted in moderate maternal weight gain $(22.09 \pm 1.87$ vs $19.48 \pm 1.31 \mathrm{~g})$ after 6 weeks on $\mathrm{HF}$ diet in C57Bl/6J dams. Glucose tolerance tests did not differ between HF-fed and N-fed mothers before mating, while glucose tolerance tests performed at the end of lactation showed significantly elevated serum glucose at 30, 60, and 120 min after the glucose bolus (data not shown), indicating development of impaired glucose tolerance during pregnancy and lactation. However, there were no differences in litter size between $\mathrm{HF}$ and $\mathrm{N}$ groups (data not shown).

Offspring The effects of maternal HF diet on offspring metabolism, body composition, BMD, and hormone levels differed by sex.

Females In females, glucose tolerance and body mass did not differ in HF-N vs N-N at either age (Fig. 1A and B). WBBMC (g) was $12 \%$ lower at 14 weeks of age and $5 \%$ lower at 26 weeks of age in HF-N vs N-N $(P<0.05$; Fig. 1$)$. However, WBBMD $\left(\mathrm{g} / \mathrm{cm}^{2}\right)$ did not differ (NS; Table 1), in part because BA $\left(\mathrm{cm}^{2}\right)$ was $11 \%$ lower in HF-N vs $\mathrm{N}-\mathrm{N}$ at 14 weeks of age $(P<0.05$; Table 1$)$. Although HF-N females had lower body fat (\%), they had higher serum leptin vs N-N at 14 weeks of age $(P<0.05$ for both;

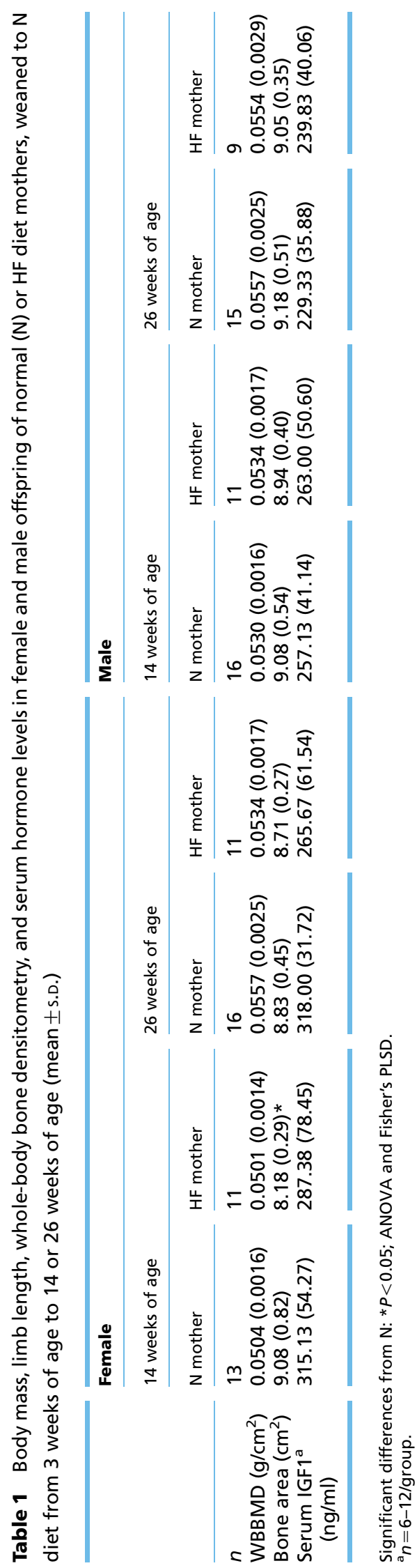

Published by Bioscientifica Ltd. http://joe.endocrinology-journals.org DOI: $10.1530 / J O E-12-0403$
C 2013 Society for Endocrinology Printed in Great Britain 
Fig. 1D and E). There were no differences in insulin or IGF1 (Fig. 1F, Table 1).

Males In males, maternal HF did not affect body mass, but glucose tolerance at 30 min was impaired at 26 weeks of age in HF-N vs N-N $(P<0.05$; Fig. 1A and B). WBBMD, WBBMC, and BA did not differ in male HF-N vs N-N at either endpoint (Fig. 1C, Table 1). Body fat (\%) was lower in HF-N at 14 weeks of age, while serum leptin was lower in HF-N at 26 weeks of age $(P<0.05$ for both; Fig. 1D and E). Serum insulin was higher in HF-N at 14 weeks and lower at 26 weeks, but serum IGF1 did not differ vs N-N $(P<0.05$; Fig. 1E, Table 1$)$.

\section{Femoral trabecular and cortical bone morphology}

Females Maternal HF diet had sex-specific effects on offspring trabecular and cortical architecture. Female HF-N had 20\% higher Tb.BV/TV (\%) at 14 weeks of age, with higher Conn.D and lower SMI, indicative of more connected, plate-like trabeculae compared with N-N $(P<0.05$ for all; Fig. 2 , Table 2$)$. These differences were no longer significant at 26 weeks of age. There were no differences in cortical bone morphology in HF-N vs N-N at either endpoint.

Males Male HF-N had 34\% higher Tb.BV/TV (\%) at 14 weeks of age $(P<0.05$; Fig. 2$)$, along with $9-10 \%$ higher Tb.N and $9-11 \%$ lower Tb.Sp at 14 and 26 weeks of age vs N-N $(P<0.05$ for all; Table 2$)$. Male HF-N also had higher Conn.D and lower SMI compared with N-N $(P<0.05$ for all; Fig. 2, Table 2$)$. In the midshaft femur, Ct.BA was $6 \%$ higher and pMOI was $15 \%$ higher in male HF-N vs N-N at 14 weeks of age $(P<0.03$; Fig. 2, Table 2), but at 26 weeks of age, there were no differences between groups.

\section{Bone strength}

Bone strength testing by three-point bending demonstrated that maternal diet had little influence on offspring adult whole bone strength. Ultimate force $(\mathrm{N})$, stiffness $(\mathrm{N} / \mathrm{mm})$, and estimated elastic modulus did not differ between HF-N and N-N in either sex at either endpoint (Table 3). Post-yield displacement was 67\% lower in HF-N vs $\mathrm{N}-\mathrm{N}$ males at 26 weeks of age $(P<0.05)$, suggesting that maternal HF diet may contribute to less brittle bones in adult male offspring.
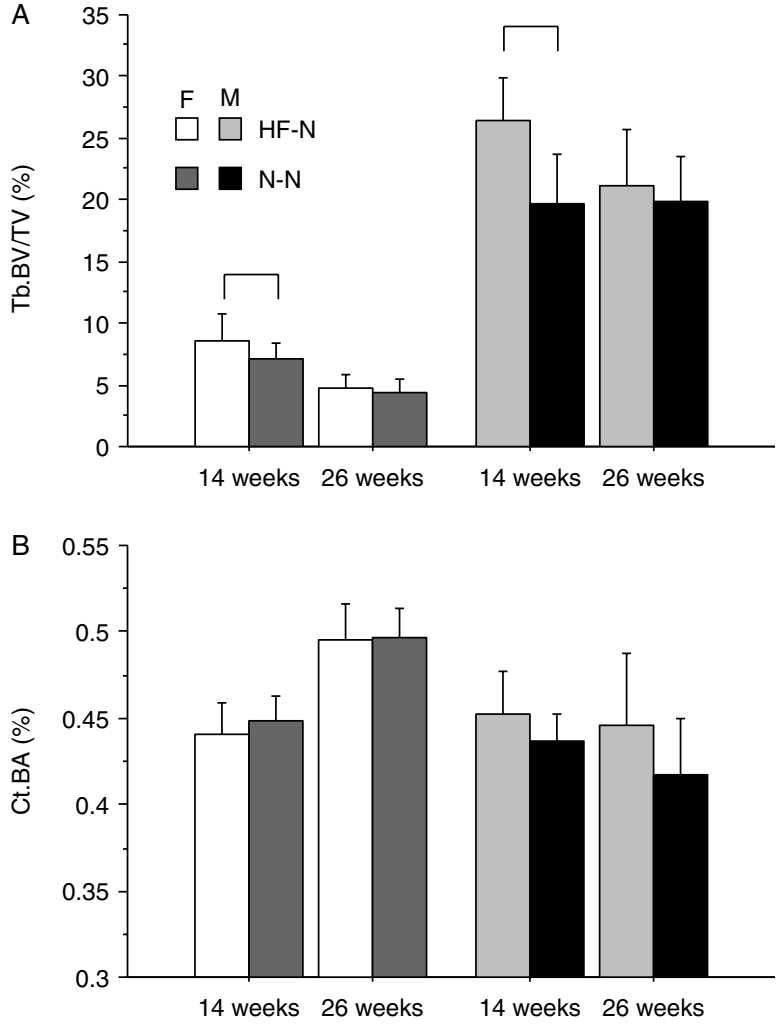

Figure 2

Trabecular and cortical bone microarchitecture in the distal and midshaft femur in female and male offspring of N-N or HF-N diet mothers, weaned to $\mathrm{N}$ diet from 3 weeks of age to 14 or 26 weeks of age. (A) Tb.BV/TV ((\%); $n=9-16 /$ group). (B) Ct.BA ((mm²); $n=9-16 /$ group). Brackets indicate significant differences $(P<0.05)$

\section{Bone histomorphometry and bone turnover markers}

Static and dynamic histomorphometry revealed that at 14 weeks of age, HF-N males had 70-80\% higher MS/BS (\%) and MAR $(\mu \mathrm{m} /$ day), and nearly threefold higher BFR/BS $\left(\mu \mathrm{m}^{3} / \mu \mathrm{m}^{2}\right.$ per year), along with $72 \%$ lower ES/BS (\%), indicating faster bone formation (Fig. 3) and slower bone resorption vs N-N males $(P<0.05$ for all; Table 4$)$. These trends were consistent with the higher BV/TV (\%) seen in this group. In female HF-N, which also had high BV/TV at 14 weeks of age, there were no differences in BFR vs N-N, but $\mathrm{ES} / \mathrm{BS}(\%)$ was $40 \%$ lower $(P<0.07)$, indicating lower osteoclast activity (Table 4). At 26 weeks of age, HF-N females had $38-45 \%$ lower MS/BS and BFR/BS vs N-N $(P<0.05$ for both; Table 4$)$, indicating slower bone formation, but, as discussed earlier, there were no significant differences in trabecular architecture at this time point.

Additional static measurements, including the N.Ob/T.Ar $\left(/ \mathrm{mm}^{2}\right)$, N.Oc/T.Ar $\left(/ \mathrm{mm}^{2}\right)$, N.Ot/T.Ar $\left(/ \mathrm{mm}^{2}\right)$,

Published by Bioscientifica Ltd. 


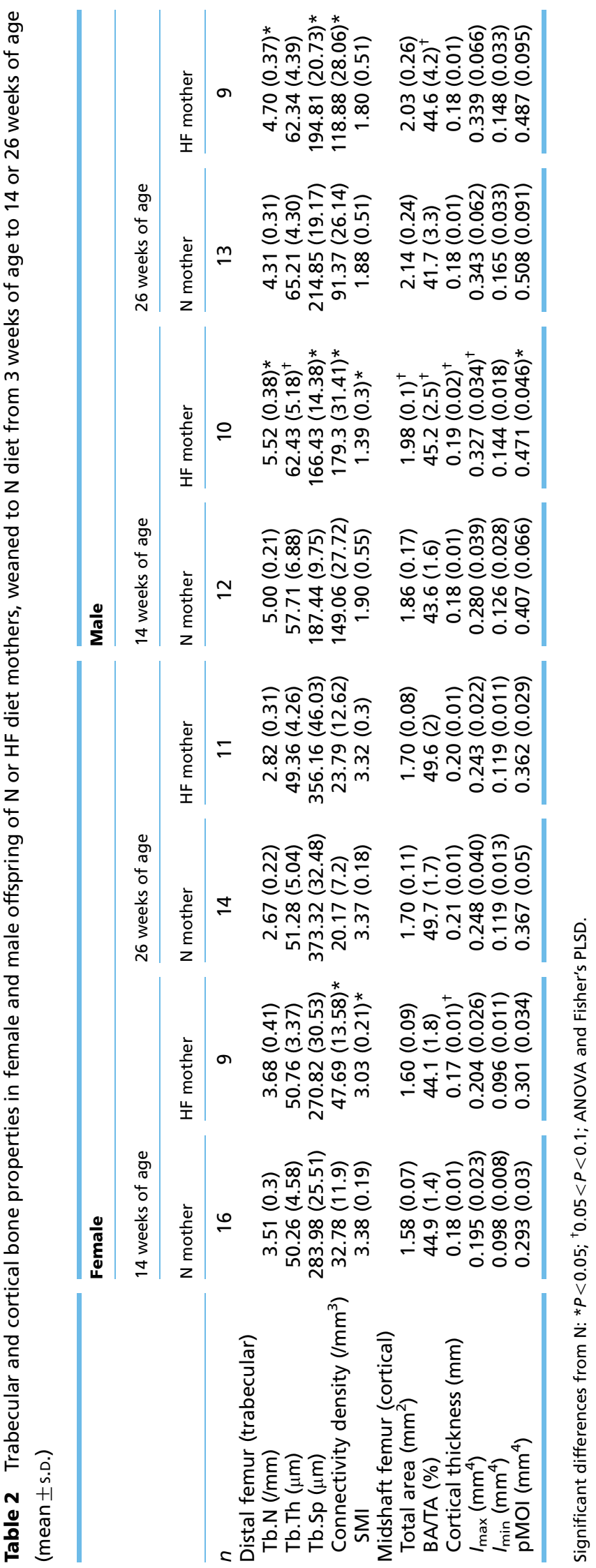

http://joe.endocrinology-journals.org DOI: 10.1530/JOE-12-0403
C) 2013 Society for Endocrinology Printed in Great Britain
N.Ad/T.Ar $\left(/ \mathrm{mm}^{2}\right)$, and mean adipocyte diameter $(\mathrm{mm})$, showed primarily age- and sex-related trends, with no apparent effect of diet (Table 4). Osteoblast number declined with age, particularly in females, while osteocyte and osteoclast numbers increased, particularly in males. Marrow adipocyte number was highly variable, with more marrow fat evident in females and with aging, but did not appear to be correlated with diet.

Serum markers of bone formation, P1NP, and bone resorption, CTX, were measured by ELISA ( $n=5$ /group). At 14 and 26 weeks of age, there were no differences in P1NP or CTX in male or female offspring of HF or $\mathrm{N}$ diet mothers.

\section{Discussion}

In this study, we tested the effects of maternal HF diet on body composition, hormone levels, and cortical and trabecular bone properties in male and female mice. Mothers were fed a HF diet beginning 6 weeks before conception and continuing until offspring were weaned at 3 weeks of age. Offspring were then fed a normal diet until 14 or 26 weeks of age. The results show that maternal HF diet has lasting effects on skeletal phenotype, even when offspring are raised on a normal diet.

Although obesity is known to be deleterious to fertility and birth rates (Bermejo-Alvarez et al. 2012), in this study, we did not observe reduced fecundity in HF-fed dams, and there were no differences in litter size between $\mathrm{HF}$ and $\mathrm{N}$ litters. Our results are consistent with previous evidence that the C57Bl/6J strain may be resistant to HF-induced reductions in fertility. For example, Tortoriello et al. (2004) found that a HF diet impaired fertility in DBA/2J but not $\mathrm{C} 57 \mathrm{Bl} / 6 \mathrm{~J}$ mice, despite glucose intolerance and insulin resistance.

Female offspring of maternal HF had lower WBBMC at 14 and 26 weeks of age and higher distal femur trabecular bone volume fraction with more connected, plate-like trabeculae at 14 weeks of age, compared with control females. Female HF-N also had evidence of lower bone formation and mineralization at 26 weeks of age compared with controls.

Male offspring of maternal HF had higher distal femur trabecular bone volume fraction, with more connected, plate-like trabeculae, higher $\mathrm{Tb} . \mathrm{N}$, and lower trabecular spacing, as well as higher midshaft cortical BA and bone strength, at 14 weeks of age, compared with control males. HF-N males also had up to threefold higher bone formation and mineralization and lower osteoclast activity compared with controls at 14 weeks of age. At 

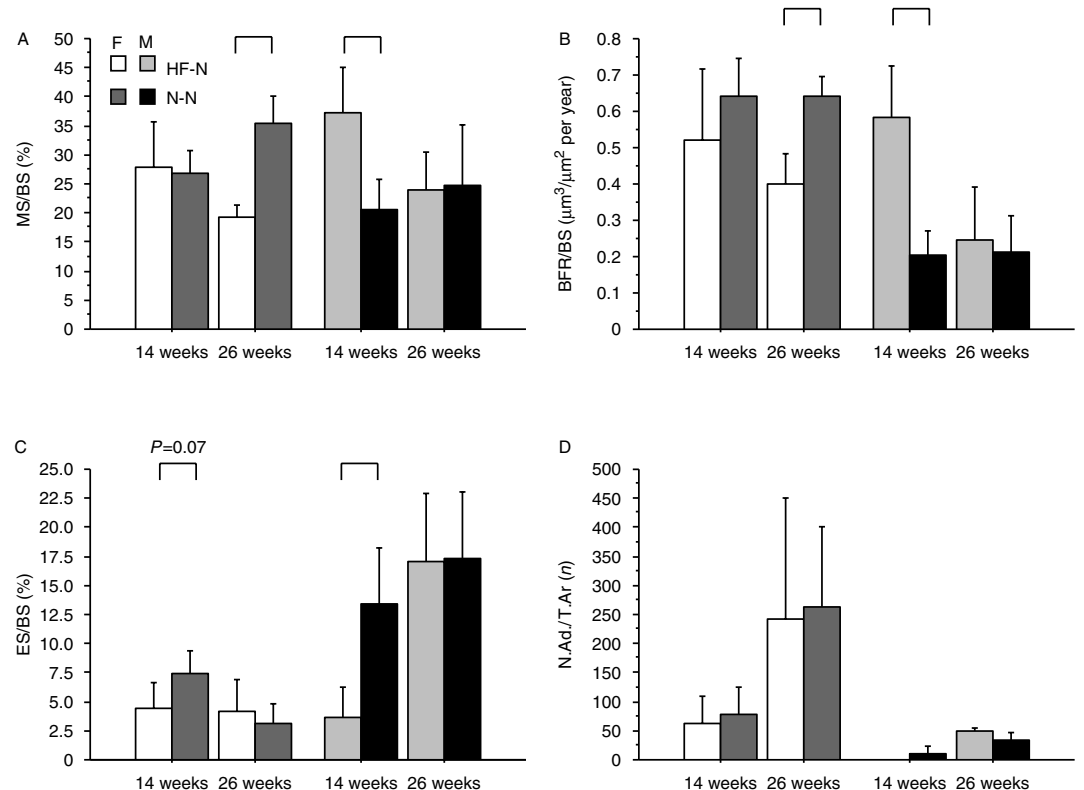

Figure 3

Dynamic histomorphometry of distal femoral metaphysis in female and male offspring of $\mathrm{N}$ or HF diet mothers, weaned to $\mathrm{N}$ diet from age 3 to 14

or 26 weeks of age. (A) MS/BS (\%), (B) BFR/BS ( $\mu \mathrm{m}^{3} / \mu \mathrm{m}^{2}$ per year), (C) $\mathrm{ES} / \mathrm{BS}$ (\%), (D) N.Ad./T.Ar ( $n)$. Brackets indicate significant differences $(P<0.05)$.

26 weeks of age, HF-N males had lower post-yield displacement in mechanical testing, suggesting greater resistance to deformation.

\section{Evidence for perinatal developmental programming}

These data demonstrate that maternal HF diet has persistent effects on offspring skeletal phenotype, potentially via developmental programming of the skeleton. However, the effects of maternal diet are complex and differ by sex, age, and compartment (trabecular vs cortical bone). Specifically, we hypothesized that offspring of HF diet mothers would exhibit higher fat mass and lower bone mass compared with offspring of $\mathrm{N}$ diet mothers, given previous evidence that maternal HF diet induces programming of obesity (Samuelsson et al. 2008, Howie et al. 2009, White et al. 2009, Jungheim et al. 2010) and that higher adiposity is correlated with lower bone mass (Wren et al. 2011). However, we did not observe higher adiposity in HF offspring of either sex and saw lower WBBMC only in females. Unexpectedly, rather than being impaired by maternal HF diet, offspring distal femur trabecular bone volume and connectivity were actually greater in HF offspring in both sexes at 14 weeks of age, along with bone formation and mineralization in males, and osteoclast activity was lower in HF mice of both sexes. Maternal HF diet had little effect on cortical bone, with the

exception of higher midshaft femoral area in HF male offspring at 14 weeks of age. This difference in compartmental response is consistent with the idea that trabecular bone is more sensitive than cortical bone to metabolic changes, perhaps due to its higher surface area:volume ratio (Compston 2001).

Although the effects of maternal HF diet persisted into adulthood, we observed that differences between HF-N and N-N offspring diminished with age. For example, both the high trabecular bone volume fraction seen in HF-N males and females and the increased bone formation and mineralization evident in HF-N males had disappeared by 26 weeks of age. This pattern suggests that maternal HF may increase skeletal acquisition in younger mice but that this benefit is not maintained in aging mice.

\section{Comparison to previous work}

Interpreting our data is challenging given that few previous animal studies have tested how a maternal HF diet affects offspring bone mass. At the end of gestation, there is evidence that fetuses of mouse dams fed a HF diet are smaller, with lower bone mass (Liang et al. 2009). A longer-term study compared mice exposed to both maternal and postnatal HF diet (HF-HF), postnatal HF diet (C-HF), or control diet (C-C) until 30 weeks of age. 


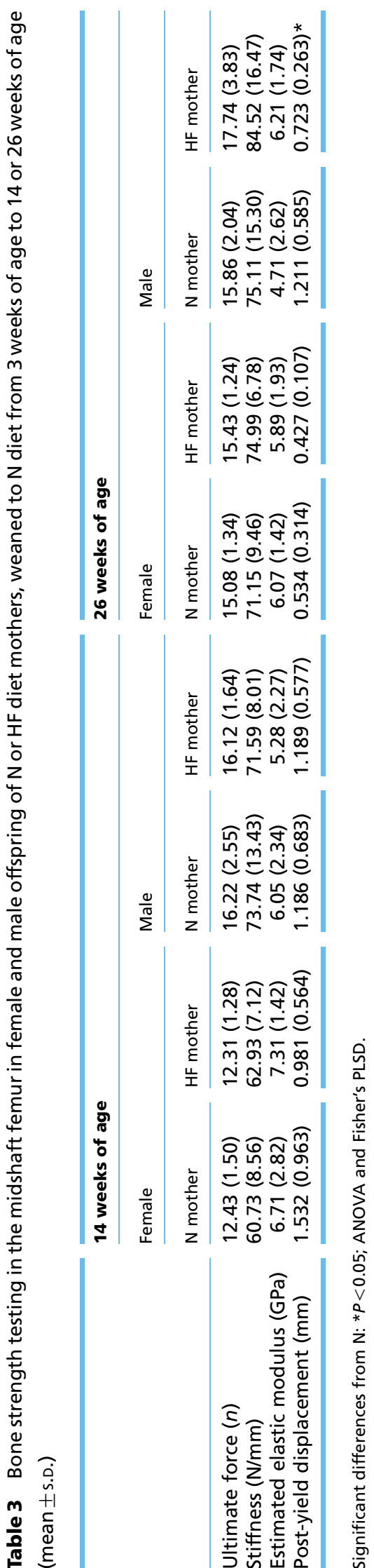

http://joe.endocrinology-journals.org DOI: $10.1530 / J O E-12-0403$
The most striking finding was markedly higher distal femur marrow adiposity in HF-HF vs controls in both sexes. HF-HF also had higher body mass and shorter, wider femurs vs controls (Lanham et al. 2010). In our study, HF diet exposure was limited to mothers, and we saw no increase in offspring marrow adiposity.

In humans, elucidating the effects of maternal HF diet on skeletal acquisition is complicated by the multiple contributors to fetal overnutrition, including maternal obesity, type 2 diabetes, and/or gestational diabetes. In general, there is evidence that large size for gestational age (LGA) is associated with changes in bone mass, although the effect of the intrauterine environment on postnatal bone properties may depend on the root cause (i.e. high glucose, high caloric intake, or both) and on whether overnutrition continues postnatally. Human LGA infants tend to have higher total body BMC and BMD vs normal sized infants, even relative to their higher body mass (Hammami et al. 2001). On the other hand, maternal fat mass and third trimester maternal fat intake are negatively associated with childhood BMD in offspring (Yin et al. 2010). The existence of perinatal programming of the skeleton in humans remains to be established.

\section{Potential mechanisms}

While our data show that a maternal HF diet induces developmental programming of bone, the possible adaptive significance of this effect remains unclear. Models of perinatal developmental programming suggest that this mechanism allows the offspring to respond to maternal cues as to what its postnatal energetic environment is likely to be (Barker 1990). Therefore, metabolic disease risk should be greatest when the maternal and postnatal environments are dissimilar (Armitage et al. 2005, Gluckman et al. 2005). For example, low birth weight followed by rapid postnatal catch-up growth is associated with greater risk of obesity and type II diabetes in humans, perhaps because offspring have a 'thrifty' phenotype in expectation of food scarcity but are actually raised with food abundance (Hales et al. 1991, Hales \& Barker 1992, Claris et al. 2010; but see also Wells et al. (2007)).

In this study, maternal HF diet was associated with lower BMC in female offspring, but male and female HF offspring also had greater trabecular bone volume fraction, and male offspring had higher rates of bone formation and greater cortical bone strength. It is not yet clear why a maternal HF diet would lead to higher bone strength. One possibility is that the maternal and
(๑) 2013 Society for Endocrinology Printed in Great Britain 


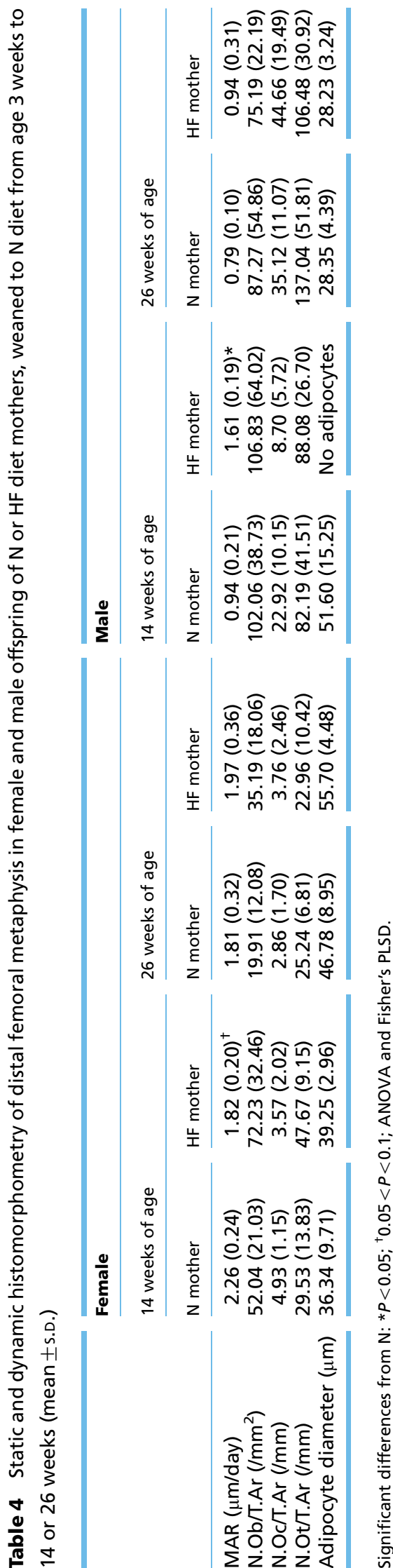

http://joe.endocrinology-journals.org DOI: $10.1530 / \mathrm{JOE}-12-0403$
(C) 2013 Society for Endocrinology Printed in Great Britain postnatal diets were not dissimilar enough to disrupt normal skeletal acquisition. Both the maternal and postnatal diets were given ad libitum and provided complete nutrition. Future studies should incorporate dissimilar diets (e.g. perinatal HF followed by postnatal caloric restriction) to test the predictive adaptive response hypothesis for the skeleton.

Another possible hypothesis is that maternal HF feeding leads to the development of higher bone strength in offspring in response to increased adiposity in offspring. Offspring from HF-N dams in our study did not differ in actual bodyweight from controls, but body fat, as a marker of adiposity, was still elevated at 14 weeks of age in male and female offspring of HF-N dams compared with controls.

Therefore, another crucial question is whether the skeletal phenotype of HF-N mice results from direct perinatal developmental programming of bone or whether we are observing secondary effects of perinatal programming of endocrine or metabolic pathways, which then influence skeletal metabolism. The fact that maternal HF-induced changes in leptin and insulin levels, as well as in bone mass, raises the possibility that the skeletal phenotype of HF-N offspring could be a secondary result of perinatal programming of hormone levels, rather than of the skeleton itself. The adipokine leptin, acting via the hypothalamus and sympathetic nervous system to modulate $\beta$-adrenergic signaling (Ducy et al. 2000, Takeda et al. 2002, Elefteriou et al. 2005) and/or to suppress brain-derived serotonin (Yadav et al. 2009), is associated with lower trabecular bone mass, while there is some evidence that peripheral leptin may be anabolic in cortical bone (Thomas et al. 1999, Cornish et al. 2002, Patel \& Elefteriou 2007). However, we observed only transient changes in leptin levels that did not appear to correlate with bone microarchitecture. For example, female HF-N had higher leptin at 14 weeks of age only, along with higher trabecular BV/TV. Given that higher leptin would be expected to cause trabecular bone loss, we think it is unlikely that this skeletal phenotype is secondary to changes in leptin.

Other potential hormonal mediators of bone mass include IGF1 and insulin. Although changes in IGF1 could certainly alter bone mass (Fall et al. 1998, Rosen 2000), we saw no effects of maternal HF on serum IGF1. However, male HF-N had higher insulin at 14 weeks of age, along with higher trabecular BV/TV and cortical bone strength. By 26 weeks of age, HF-N had lower insulin (and leptin) levels and no differences in trabecular or cortical bone vs N-N. It has been suggested that insulin has anabolic

Published by Bioscientifica Ltd. 
effects in bone (Thrailkill et al. 2005), so it is possible that insulin is partially responsible for the bone changes we observed in males.

Perinatal programming could also alter postnatal bone mass directly, such as by an increase or decrease in bone cell number, proliferation, and growth rate (Javaid \& Cooper 2002, Sayer \& Cooper 2005). While HF-N offspring did not have higher osteoblast numbers, male HF-N had up to threefold higher bone formation and mineralization and lower osteoclast activity compared with controls at 14 weeks of age, suggesting higher growth rate. However, female HF-N had normal or lower bone formation and mineralization compared with controls.

A final possibility is that maternal HF might alter offspring bone mass through epigenetic mechanisms. Although much more research is needed, there is some evidence that DNA methylation and other epigenetic mechanisms can induce lifelong changes in transcription of genes influencing bone mass. Specifically, a maternal HF diet in rats has been shown to alter transcription of genes including the leptin receptor (Lepr), proopiomelanocortin (Pomc), neuropeptide Y (Npy), and signal transducer and activator of transcription 3 (Stat3), which could alter both feeding behavior and bone mass postnatally (Chen et al. 2008, Page et al. 2009). Perhaps most strikingly, recent studies in mice have demonstrated that maternal HF diet in gestation or lactation can transmit both insulin resistance and increased body length to future generations via epigenetic inheritance (Dunn \& Bale 2009, Pentinat et al. 2010).

\section{Limitations and alternatives}

There are some limitations to our data, most importantly the fact that skeletal phenotype was assessed only in adulthood (14 and 26 weeks of age). Future studies, including time points during the period of rapid skeletal growth, as well as longitudinal in vivo bone density measurements, will help to elucidate how maternal HF diet affects offspring bone mass as it is being acquired. Also, as noted earlier, more disparate combinations of diet may be needed to reveal all the effects of perinatal programming on bone.

Future studies should also consider other hormones that could underlie the effects of perinatal diet on skeletal acquisition, including glucocorticoids (Phillips et al. 1998) and osteocalcin, which has recently been identified as a bone-derived hormone that controls energy metabolism (Lee et al. 2007, Ferron et al. 2008). Some data demonstrate that osteocalcin is produced by adipocytes as well as osteoblasts, suggesting that both fat and bone may contribute to glucose homeostasis via osteocalcin production (Foresta et al. 2010).

Finally, this study did not directly measure whether maternal HF diet induced epigenetic changes in offspring bone. In future studies, direct assessment of epigenetic changes such as histone modification or DNA methylation will allow us to test the hypothesis that perinatal programming of the skeleton occurs via epigenetic mechanisms.

\section{Conclusions}

Maternal HF diet during gestation and lactation alters offspring skeletal phenotype at 3-6 months of age, even when pups are raised on a normal postnatal diet. A maternal HF diet may impair postnatal cortical bone acquisition in pups but also slow age-related trabecular bone loss. Our data support the hypothesis that maternal diet alters postnatal skeletal homeostasis, perhaps via perinatal developmental programming. Further work is needed to identify the precise mechanisms underlying this phenomenon.

\section{Declaration of interest}

The authors declare that there is no conflict of interest that could be perceived as prejudicing the impartiality of the research reported.

\section{Funding}

This study was supported by NIH F32HD060419, T32DK007028, and RC1AR058389, and the Restracomp program, SickKids Research Institute.

\section{Acknowledgements}

The authors wish to thank Michael Ke Wang and Celeste Owen for excellent technical support.

\section{References}

Armitage JA, Taylor PD \& Poston L 2005 Experimental models of developmental programming: consequences of exposure to an energy rich diet during development. Journal of Physiology 565 3-8. (doi:10.1113/jphysiol.2004.079756)

Barker DJ 1990 The fetal and infant origins of adult disease. BMJ 301111. (doi:10.1136/bmj.301.6761.1111)

Bermejo-Alvarez P, Rosenfeld CS \& Roberts RM 2012 Effect of maternal obesity on estrous cyclicity, embryo development and blastocyst gene expression in a mouse model. Human Reproduction 27 3513-3522. (doi:10.1093/humrep/des327)

Boney CM, Verma A, Tucker R \& Vohr BR 2005 Metabolic syndrome in childhood: association with birth weight, maternal obesity, and gestational diabetes mellitus. Pediatrics 115 e290-e296. (doi:10.1542/ peds.2004-1808) http://joe.endocrinology-journals.org DOI: 10.1530/JOE-12-0403
(C) 2013 Society for Endocrinology Printed in Great Britain
Published by Bioscientifica Ltd 
Bonnet N, Pierroz DD \& Ferrari SL 2008 Adrenergic control of bone remodeling and its implications for the treatment of osteoporosis. Journal of Musculoskeletal \& Neuronal Interactions 8 94-104.

Bouxsein ML, Rosen CJ, Turner CH, Ackert CL, Shultz KL, Donahue LR, Churchill G, Adamo ML, Powell DR, Turner RT et al. 2002 Generation of a new congenic mouse strain to test the relationships among serum insulin-like growth factor I, bone mineral density, and skeletal morphology in vivo. Journal of Bone and Mineral Research 17 570-579. (doi:10.1359/jbmr.2002.17.4.570)

Bouxsein ML, Pierroz DD, Glatt V, Goddard DS, Cavat F, Rizzoli R \& Ferrari SL $2005 \beta$-Arrestin2 regulates the differential response of cortical and trabecular bone to intermittent PTH in female mice. Journal of Bone and Mineral Research 20 635-643. (doi:10.1359/JBMR.041204)

Bouxsein ML, Devlin MJ, Glatt V, Dhillon H, Pierroz DD \& Ferrari SL 2009 Mice lacking $\beta$-adrenergic receptors have increased bone mass, but are not protected from deleterious skeletal effects of ovariectomy. Endocrinology 150 144-152. (doi:10.1210/en.2008-0843)

Bouxsein ML, Boyd SK, Christiansen BA, Guldberg RE, Jepsen KJ \& Muller R 2010 Guidelines for assessment of bone microstructure in rodents using micro-computed tomography. Journal of Bone and Mineral Research $\mathbf{2 5}$ 1468-1486. (doi:10.1002/jbmr.141)

Cao JJ 2011 Effects of obesity on bone metabolism. Journal of Orthopaedic Surgery and Research 6 30. (doi:10.1186/1749-799X-6-30)

Chen H, Simar D, Lambert K, Mercier J \& Morris MJ 2008 Maternal and postnatal overnutrition differentially impact appetite regulators and fuel metabolism. Endocrinology 149 5348-5356. (doi:10.1210/en.2008-0582)

Chevalley T, Bonjour JP, Ferrari S \& Rizzoli R 2009 Deleterious effect of late menarche on distal tibia microstructure in healthy 20-year-old and premenopausal middle-aged women. Journal of Bone and Mineral Research 24 144-152. (doi:10.1359/jbmr.080815)

Claris O, Beltrand J \& Levy-Marchal C 2010 Consequences of intrauterine growth and early neonatal catch-up growth. Seminars in Perinatology 34 207-210. (doi:10.1053/j.semperi.2010.02.005)

Compston JE 2001 Sex steroids and bone. Physiological Reviews 81 419-447.

Cooper C, Westlake S, Harvey N, Javaid K, Dennison E \& Hanson M 2006 Review: developmental origins of osteoporotic fracture. Osteoporosis International 17 337-347. (doi:10.1007/s00198-005-2039-5)

Cornish J, Callon KE, Bava U, Lin C, Naot D, Hill BL, Grey AB, Broom N, Myers DE, Nicholson GC et al. 2002 Leptin directly regulates bone cell function in vitro and reduces bone fragility in vivo. Journal of Biological Chemistry 175 405-415.

Ducy P, Amling M, Takeda S, Priemel M, Schilling AF, Beil FT, Shen J, Vinson C, Rueger JM \& Karsenty G 2000 Leptin inhibits bone formation through a hypothalamic relay: a central control of bone mass. Cell 100 197-207. (doi:10.1016/S0092-8674(00)81558-5)

Dunn GA \& Bale TL 2009 Maternal high-fat diet promotes body length increases and insulin insensitivity in second-generation mice. Endocrinology 150 4999-5009. (doi:10.1210/en.2009-0500)

Elefteriou F, Ahn JD, Takeda S, Starbuck M, Yang X, Liu X, Kondo H, Richards WG, Bannon TW, Noda M et al. 2005 Leptin regulation of bone resorption by the sympathetic nervous system and CART. Nature 434 514-520. (doi:10.1038/nature03398)

Fall C, Hindmarsh P, Dennison E, Kellingray S, Barker D \& Cooper C 1998 Programming of growth hormone secretion and bone mineral density in elderly men: a hypothesis. Journal of Clinical Endocrinology and Metabolism 83 135-139. (doi:10.1210/jc.83.1.135)

Ferrari SL, Pierroz DD, Glatt V, Goddard DS, Bianchi EN, Lin FT, Manen D \& Bouxsein ML 2005 Bone response to intermittent parathyroid hormone is altered in mice null for $\beta$-arrestin2. Endocrinology 146 1854-1862. (doi:10.1210/en.2004-1282)

Ferron M, Hinoi E, Karsenty G \& Ducy P 2008 Osteocalcin differentially regulates $\beta$ cell and adipocyte gene expression and affects the development of metabolic diseases in wild-type mice. PNAS $\mathbf{1 0 5}$ 5266-5270. (doi:10.1073/pnas.0711119105)

Foresta C, Strapazzon G, De Toni L, Gianesello L, Calcagno A, Pilon C, Plebani M \& Vettor R 2010 Evidence for osteocalcin production by

http://joe.endocrinology-journals.org DOI: $10.1530 / J O E-12-0403$
(C) 2013 Society for Endocrinology Printed in Great Britain adipose tissue and its role in human metabolism. Journal of Clinical Endocrinology and Metabolism 95 3502-3506. (doi:10.1210/jc.2009-2557)

Gazzerro E, Pereira RC, Jorgetti V, Olson S, Economides AN \& Canalis E 2005 Skeletal overexpression of gremlin impairs bone formation and causes osteopenia. Endocrinology 146 655-665. (doi:10.1210/en.2004-0766)

Glatt V, Canalis E, Stadmeyer L \& Bouxsein ML 2007 Age-related changes in trabecular architecture differ in female and male C57BL/6J mice. Journal of Bone and Mineral Research 22 1197-1207. (doi:10.1359/jbmr. 070507)

Gluckman PD, Cutfield W, Hofman P \& Hanson MA 2005 The fetal, neonatal, and infant environments - the long-term consequences for disease risk. Early Human Development 81 51-59. (doi:10.1016/ j.earlhumdev.2004.10.003)

Hales CN \& Barker DJ 1992 Type 2 (non-insulin-dependent) diabetes mellitus: the thrifty phenotype hypothesis. Diabetologia 35 595-601. (doi:10.1007/BF00400248)

Hales CN, Barker DJ, Clark PM, Cox LJ, Fall C, Osmond C \& Winter PD 1991 Fetal and infant growth and impaired glucose tolerance at age 64. BMJ 303 1019-1022. (doi:10.1136/bmj.303.6809.1019)

Hammami M, Walters JC, Hockman EM \& Koo WW 2001 Disproportionate alterations in body composition of large for gestational age neonates. Journal of Pediatrics 138 817-821. (doi:10.1067/mpd.2001.114018)

Hamrick MW 2004 Leptin, bone mass, and the thrifty phenotype. Journal of Bone and Mineral Research 19 1607-1611. (doi:10.1359/JBMR.040712)

Howie GJ, Sloboda DM, Kamal T \& Vickers MH 2009 Maternal nutritional history predicts obesity in adult offspring independent of postnatal diet. Journal of Physiology 587 905-915. (doi:10.1113/jphysiol. 2008.163477)

Javaid MK \& Cooper C 2002 Prenatal and childhood influences on osteoporosis. Best Practice \& Research. Clinical Endocrinology \& Metabolism 16 349-367. (doi:10.1053/beem.2002.0199)

Jungheim ES, Schoeller EL, Marquard KL, Louden ED, Schaffer JE \& Moley KH 2010 Diet-induced obesity model: abnormal oocytes and persistent growth abnormalities in the offspring. Endocrinology $\mathbf{1 5 1}$ 4039-4046. (doi:10.1210/en.2010-0098)

Lanham SA, Roberts C, Hollingworth T, Sreekumar R, Elahi MM, Cagampang FR, Hanson MA \& Oreffo RO 2010 Maternal high-fat diet: effects on offspring bone structure. Osteoporosis International 21 1703-1714. (doi:10.1007/s00198-009-1118-4)

Lee NK, Sowa H, Hinoi E, Ferron M, Ahn JD, Confavreux C, Dacquin R, Mee PJ, McKee MD, Jung DY et al. 2007 Endocrine regulation of energy metabolism by the skeleton. Cell 130 456-469. (doi:10.1016/ j.cell.2007.05.047)

Liang C, Oest ME, Jones JC \& Prater MR 2009 Gestational high saturated fat diet alters C57BL/6 mouse perinatal skeletal formation. Birth Defects Research. Part B, Developmental and Reproductive Toxicology 86 362-369. (doi:10.1002/bdrb.20204)

Lucas A 1991 Programming by early nutrition in man. Ciba Foundation Symposium 156 38-50 (discussion 50-55).

Matthews JN, Altman DG, Campbell MJ \& Royston P 1990 Analysis of serial measurements in medical research. BMJ 300 230-235. (doi:10.1136/ bmj.300.6719.230)

Motyl KJ \& McCabe LR 2009 Leptin treatment prevents type I diabetic marrow adiposity but not bone loss in mice. Journal of Cellular Physiology 218 376-384. (doi:10.1002/jcp.21608)

Ogden CL Carroll MD, McDowell MA \& Flegal KM 2007 Obesity among adults in the United States - no change since 2003-2004 (NCHS data brief no 1). Hyattsville, MD: National Center for Health Statistics.

Ozanne SE, Fernandez-Twinn D \& Hales CN 2004 Fetal growth and adult diseases. Seminars in Perinatology 28 81-87. (doi:10.1053/j.semperi. 2003.10.015)

Page KC, Malik RE, Ripple JA \& Anday EK 2009 Maternal and postweaning diet interaction alters hypothalamic gene expression and modulates response to a high-fat diet in male offspring. American Journal of Physiology. Regulatory, Integrative and Comparative Physiology 297 R1049-R1057. (doi:10.1152/ajpregu.90585.2008) 
Parfitt AM, Drezner MK, Glorieux FH, Kanis JA, Malluche H, Meunier PJ, Ott SM \& Recker RR 1987 Bone histomorphometry: standardization of nomenclature, symbols, and units. Report of the ASBMR Histomorphometry Nomenclature Committee. Journal of Bone and Mineral Research 2 595-610. (doi:10.1002/jbmr.5650020617)

Patel MS \& Elefteriou F 2007 The new field of neuroskeletal biology. Calcified Tissue International 80 337-347. (doi:10.1007/s00223-007-9015-3)

Pentinat T, Ramon-Krauel M, Cebria J, Diaz R \& Jimenez-Chillaron JC 2010 Transgenerational inheritance of glucose intolerance in a mouse model of neonatal overnutrition. Endocrinology 151 5617-5623. (doi:10.1210/ en.2010-0684)

Phillips DI, Barker DJ, Fall CH, Seckl JR, Whorwood CB, Wood PJ \& Walker BR 1998 Elevated plasma cortisol concentrations: a link between low birth weight and the insulin resistance syndrome? Journal of Clinical Endocrinology and Metabolism 83 757-760. (doi:10.1210/jc.83.3.757)

Rosen CJ 2000 IGF-I and osteoporosis. Clinics in LaboratoryMedicine 20 591-602.

Rosen CJ \& Bouxsein ML 2006 Mechanisms of disease: is osteoporosis the obesity of bone? Nature Clinical Practice. Rheumatology $235-43$. (doi:10.1038/ncprheum0070)

Samuelsson AM, Matthews PA, Argenton M, Christie MR, McConnell JM, Jansen EH, Piersma AH, Ozanne SE, Twinn DF, Remacle C et al. 2008 Diet-induced obesity in female mice leads to offspring hyperphagia, adiposity, hypertension, and insulin resistance: a novel murine model of developmental programming. Hypertension 51 383-392. (doi:10.1161/HYPERTENSIONAHA.107.101477)

Sayer AA \& Cooper C 2005 Fetal programming of body composition and musculoskeletal development. Early Human Development 81 735-744. (doi:10.1016/j.earlhumdev.2005.07.003)

Selker F \& Carter DR 1989 Scaling of long bone fracture strength with animal mass. Journal of Biomechanics 22 1175-1183. (doi:10.1016/00219290(89)90219-4)

Takeda S, Elefteriou F, Levasseur R, Liu X, Zhao L, Parker KL, Armstrong D, Ducy P \& Karsenty G 2002 Leptin regulates bone formation via the sympathetic nervous system. Cell 111 305-317. (doi:10.1016/S00928674(02)01049-8)

Thomas T, Gori F, Khosla S, Jensen MD, Burguera B \& Riggs BL 1999 Leptin acts on human marrow stromal cells to enhance differentiation to osteoblasts and to inhibit differentiation to adipocytes. Endocrinology 140 1630-1638. (doi:10.1210/en.140.4.1630)

Thrailkill KM, Lumpkin CK Jr, Bunn RC, Kemp SF \& Fowlkes JL 2005 Is insulin an anabolic agent in bone? Dissecting the diabetic bone for clues American Journal of Physiology. Endocrinology and Metabolism 289 E735-E745. (doi:10.1152/ajpendo.00159.2005)

Tortoriello DV, McMinn J \& Chua SC 2004 Dietary-induced obesity and hypothalamic infertility in female DBA/2J mice. Endocrinology 145 1238-1247. (doi:10.1210/en.2003-1406)

U. S. Department of Health and Human Services (2004) Bone Health and Osteoporosis: A Report of the Surgeon General. (U.S. Department of Health and Human Services, Office of the Surgeon General, Rockville, MD), pp 1-436.

Wells JC, Chomtho S \& Fewtrell MS 2007 Programming of body composition by early growth and nutrition. Proceedings of the Nutrition Society 66 423-434. (doi:10.1017/S0029665107005691)

White CL, Purpera MN \& Morrison CD 2009 Maternal obesity is necessary for programming effect of high-fat diet on offspring. American Journal of Physiology. Regulatory, Integrative and Comparative Physiology 296 R1464-R1472. (doi:10.1152/ajpregu.91015.2008)

Wren TA, Chung SA, Dorey FJ, Bluml S, Adams GB \& Gilsanz V 2011 Bone marrow fat is inversely related to cortical bone in young and old subjects. Journal of Clinical Endocrinology and Metabolism 96 782-786. (doi:10.1210/jc.2010-1922)

Yadav VK, Oury F, Suda N, Liu ZW, Gao XB, Confavreux C, Klemenhagen KC, Tanaka KF, Gingrich JA, Guo XE et al. 2009 A serotonin-dependent mechanism explains the leptin regulation of bone mass, appetite, and energy expenditure. Cell 138 976-989. (doi:10.1016/j.cell.2009. 06.051)

Yadav VK, Oury F, Tanaka KF, Thomas T, Wang Y, Cremers S, Hen R, Krust A, Chambon P \& Karsenty G 2011 Leptin-dependent serotonin control of appetite: temporal specificity, transcriptional regulation, and therapeutic implications. Journal of Experimental Medicine 208 41-52. (doi:10.1084/jem.20101940)

Yin J, Dwyer T, Riley M, Cochrane J \& Jones G 2010 The association between maternal diet during pregnancy and bone mass of the children at age 16. European Journal of Clinical Nutrition 64 131-137. (doi:10.1038/ejcn.2009.117)

Received in final form 28 January 2013

Accepted 31 January 2013

Accepted Preprint published online 31 January 2013
C 2013 Society for Endocrinology Printed in Great Britain 